\title{
ACúmulo de Nutrientes Pelo Cafeeiro sob INTerferênCia de Plantas Daninhas ${ }^{1}$
}

\author{
Nutrient Contents of Coffee Plants Under Weed Interference \\ RONCHI, C.P. ${ }^{2}$, TERRA, A.A. ${ }^{4}$; SILVA. A.A. ${ }^{3}$ e FERREIRA, L.R. ${ }^{3}$
}

\begin{abstract}
RESUMO - As plantas jovens de café são muito sensiveis à interferência das plantas daninhas, devido à forte competição por nutrientes que se estabelece entre essas plantas. Este trabalho teve como objetivo, portanto, avaliar os efeitos da interferência de sete espécies de plantas daninhas no conteúdo relativo (CR) de macro e micronutrientes, na massa seca da parte aérea de plantas de café. Aos 30 dias após o transplantio das mudas de café, em vasos contendo $12 \mathrm{~L}$ de substrato, fez-se o transplantio e/ou a semeadura das espécies daninhas, em seis densidades $(0,1,2,3,4$ e 5 plantas por vaso). Os periodos de convivência, desde o transplantio ou emergência das plantas daninhas até a colheita das plantas, foram de 77 dias - Bidens pilosa, 180 dias - Commelina diffusa, 82 dias - Leonurus sibiricus, 68 dias - Nicandra physaloides, 148 dias - Richardia brasiliensise 133 dias - Sida rhombifolia. B. pilosa, C. diffusa, $L$. sibiricus e $R$. brasiliensis, mesmo em baixas densidades, acarretaram decréscimos consideráveis no conteúdo relativo de nutrientes de plantas de café. B. pilosa foi a planta daninha que extraiu a maior quantidade de nutrientes, enquanto $N$. physaloides e S. rhombifolia foram as espécies que causaram menor interferência ao cafeeiro. O grau de interferência variou com a espécie e com a densidade das plantas daninhas.
\end{abstract}

Palavras-chave: competição, período de convivência, nutrição mineral.

\begin{abstract}
Young coffee plants are very sensitive to weed interference due to the high nutrient competition among these plants. This work was conducted to evaluate the interference effects of seven weed species on the relative contents (RC) of macro and micro-nutrients in coffee shoot dry matter. At 30 days after coffee seedling transplantation in $12 \mathrm{~L}$ pots, the weeds were transplanted to or sowed in those pots $(0,1,2,3,4$ and 5 plants per pot). The weedy periods, from weed transplantation or emergence to plant harvesting, were 77 days - Bidens pilosa, 180 days - Commelina diffusa, 82 days - Leonurus sibiricus, 68 days - Nicandra physaloides, 148 days - Richardia brasiliensis and 133 days - Sida rhombifolia. B. pilosa, C. diffusa, $\boldsymbol{L}$. sibiricus and $\boldsymbol{R}$. brasiliensis caused considerable decreases in the nutrient $R C$ of the coffee plants, even at low densities. B. pilosa absorved the highest nutrient amounts, while $\mathbf{N}$. physaloides and S. rhombifolia caused the least interference in coffee plants. The degree of interference depended both on the species and density of the weeds.
\end{abstract}

Key words: competition, weedy periods, and mineral nutrition.

\section{INTRODUÇÃO}

Raramente são encontradas, no agroecossistema, plantas isoladas. Elas coexistem com outras plantas em associações de espécies iguais ou diferentes. Nessa condição, podem ocorrer diferentes tipos de interações entre as espécies, podendo essas ser positivas, negativas e neutras. O termo genérico que caracteriza as interações entre espécies ou populações é denominado interferência. É o efeito que a presença de uma planta exerce no

1 Recebido para publicação em 20.3.2003 e na forma revisada em 11.8.2003.

2 Doutorando, Departamento de Fisiologia Vegetal da Universidade Federal de Viçosa - UFV, 36571-000 Viçosa-MG; ${ }^{3}$ Prof., Departamento de Fitotecnia - UFV; ${ }^{4}$ Bolsista de iniciação científica, Departamento de Fitotecnia - UFV. 
crescimento e desenvolvimento de uma planta vizinha. A interferência pode ser expressa pela alteração na taxa de crescimento ou na arquitetura da planta, que resulta de uma mudança no ambiente devido à presença de outras plantas. Geralmente não se estuda o porquê das mudanças que ocorrem no ambiente, mas apenas as respostas das plantas a essas alteracões (Radosevich al., 1996).

Dentre as várias formas possiveis de interferência que ocorrem entre plantas daninhas e cultura, três representam os efeitos negativos da interação: competição, amensalismo e parasitismo, sendo a primeira a forma mais estudada (Radosevich et al., 1996). McNaughton \& Wolf (1973) definem competição como a interação biológica que ocorre entre dois ou mais indivíduos quando os recursos são limitados ou quando a qualidade destes varia e a demanda é dependente da qualidade. Segundo Barbour et al. (1987), competição é o efeito mutuamente adverso de plantas que utilizam um recurso escasso. Plantas denominadas 'boas competidoras' são aquelas que se utilizam de um recurso rapidamente ou que são capazes de continuar a crescer mesmo com baixos níveis de recursos de produção (Radosevich et al., 1996).

Recursos de produção são os fatores encontrados no ambiente, como luz, água e nutrientes. Uma vez que o crescimento, tanto da cultura quanto das plantas daninhas, após a germinação, depende da habilidade dessas plantas em extrair os recursos existentes no ambiente em que vivem - e na maioria das vezes o suprimento desses recursos é limitado, até mesmo para o próprio desenvolvimento da cultura -, estabelece-se, a partir de então, a competição. Essa limitação de recursos pode ser causada pela sua indisponibilidade, pelo suprimento deficiente ou pela presença de plantas daninhas. Estas, por sua vez, podem exaurir um recurso já insuficiente ou criar deficiência onde existia quantidade suficiente do recurso para um único indivíduo. Assim, qualquer planta daninha que se estabeleça na cultura vai usar parte dos fatores de produção, quando limitados no meio, podendo reduzir a produtividade desta (Radosevich et al., 1996).

Para que ocorra competição é necessário que haja suficiente sobreposição dos nichos dos indivíduos envolvidos, de forma que eles utilizem os mesmos recursos (McNaughton \& Wolf, 1973). A competição somente se estabelece quando a intensidade de exigência de recursos do meio, pelos competidores, é maior que a capacidade do meio em fornecer esses recursos, ou quando um dos competidores impede o acesso por parte do outro competidor, como acontece, por exemplo, em condições de sombreamento. $\mathrm{Na}$ realidade, a competição entre a planta daninha e a cultivada afeta as duas, porém a espécie daninha quase sempre supera a cultivada (Pitelli, 1985). Como exemplo, vários são os efeitos de interferência das plantas daninhas sobre a cultura do café (Pereira \& Jones, 1954; Gallo et al., 1958; Blanco et al., 1982; Friessleben et al., 1991; Brighenti, 1995; Toledo et al., 1996).

Em estudos de interferência de plantas daninhas nas plantas cultivadas é muito importante o conhecimento dos fatores que influenciam o grau de competição das espécies daninhas. Dessa forma, o homem poderá interferir no equilíbrio da competição, permitindo, assim, que a planta cultivada seja beneficiada na sua luta pela obtenção dos elementos do ambiente (Blanco \& Oliveira, 1978). O grau de interferência normalmente é medido em relação à produção da planta cultivada e pode ser definido como a redução percentual da produção econômica de determinada cultura, provocada pela interferência da comunidade daninha (Pitelli, 1985).

Dentre os vários fatores que determinam o grau de competição, merecem destaque o período de convivência, ou período de competição, e a densidade de plantas daninhas. O periodo de competição refere-se à época em que as plantas daninhas competem com as plantas cultivadas pelos fatores de crescimento (Blanco, 1972). Blanco et al. (1982) demonstraram que, nas primeiras quatro safras, em lavouras localizadas em regiões como a Sudeste, que apresentam estações "das águas" e da "seca" bem definidas, o período de convivência situou-se entre os meses de outubro e março, coincidindo com o período de maior precipitação e, também, com a floração e frutificação do cafeeiro. Sugeriram, ainda, que o aumento na produção de café é proporcional ao aumento do número de meses em que a lavoura fica livre (sem competição) de plantas daninhas, no período de outubro a abril. 
A densidade, por sua vez, é definida como o número de indivíduos por unidade de área. De acordo com Zakharenko (1969), a produção de uma cultura aumenta inversamente com o grau de infestação, segundo a fórmula $\mathrm{Yx}=\mathrm{Y}_{0}$ . a x, em que $Y_{x}$ é a produção de uma cultura infestada por plantas daninhas; $\mathrm{x}$, a infestação (em número ou biomassa de plantas daninhas por unidade de área); $\mathrm{Y}_{0}$, a produção da cultura sem interferência de plantas daninhas; e a, um coeficiente $(<1)$ que expressa a habilidade competitiva da cultura em relação às plantas daninhas (determinado experimentalmente). Essa fórmula permite estimar a perda de produção causada pelas plantas daninhas e o aumento de produção proporcionado, por exemplo, pela aplicação de herbicidas.

Existem vários métodos para se estudar a competição entre diferentes espécies de plantas, e cada um apresenta um tipo característico de bioensaio, no qual a resposta de uma espécie é usada para descrever a influência de outras. Esses métodos agrupam-se em quatro tipos comuns de experimentos: "aditivos", "substitutivos", "sistemáticos" e "vizinhança", sendo os primeiros os mais comuns e utilizados para se estudar a competição entre plantas daninhas e plantas cultivadas (Harper, 1977; Radosevich, 1987; Cousens, 1991; Radosevich et al., 1996).

O experimento aditivo consiste de duas espécies de plantas crescendo juntas num determinado ambiente, em que a densidade de uma é mantida constante e a da outra é variável. A espécie cuja densidade permanece constante age como um indicador comparativo da agressividade e competitividade da outra espécie. Esse tipo de ensaio é de grande importância no contexto agronômico, uma vez que simula a situação de uma cultura sujeita a diversos níveis de infestação por plantas daninhas (Harper, 1977; Radosevich, 1987).

O objetivo deste trabalho foi determinar os efeitos da interferência, especificamente da competição, de diversas espécies de plantas daninhas no conteúdo relativo de macro e micronutrientes em mudas de café, utilizandose do "método aditivo" de estudo da competição entre plantas.

\section{MATERIAL E MÉTODOS}

Este trabalho foi realizado em casa de vegetação (cobertura de polietileno transparente e laterais protegidas com sombrite $50 \%$ ), em Viçosa ( $20^{\circ} 45^{\prime}$ S, e $650 \mathrm{~m}$ de altitude), Minas Gerais. As mudas de café (Coffea arabica), cultivar Catuaí Vermelho, no estádio de cinco pares de folhas definitivas, foram plantadas em vasos de polietileno, contendo $12 \mathrm{~L}$ de substrato (solo + matéria orgânica + fertilizantes + corretivos). Foram aplicados ao solo (LVA), após peneirá-lo, $3,6 \mathrm{~kg} \mathrm{~m}^{-3}$ de calcário dolomítico, para suprir a necessidade de calagem de 2,4 t ha-1 , conforme análise química apresentada na Tabela 1. Foi feita adubação com $1,0 \mathrm{~kg} \mathrm{~m}^{-3}$ de $\mathrm{P}_{2} \mathrm{O}_{5}$, na forma de superfostato simples. Adicionou-se, ainda, matéria orgânica (esterco bovino) na proporção de 3,5:1 (solo: esterco). Após o pegamento das mudas, foram feitas duas aplicações de $\mathrm{N}$ em cobertura, em intervalos de 45 dias, na dose de 3,0 g vaso $^{-1}$, utilizando-se como fonte de $\mathrm{N}$ o sulfato de amônio. As irrigações foram realizadas diariamente, por sistema automático de microaspersão.

Foram estudadas seis espécies de plantas daninhas: Bidens pilosa, Commelina diffusa, Leonurus sibiricus, Richardia brasiliensis, Nicandra physaloides e Sida rhombifolia. Cada espécie foi avaliada separadamente, em sete

Tabela 1 - Características químicas do solo utilizado no preparo do substrato para enchimento dos vasos

\begin{tabular}{|c|c|c|c|c|c|c|c|c|c|c|c|c|c|c|c|c|}
\hline \multicolumn{17}{|c|}{ Análise Química } \\
\hline \multirow{2}{*}{$\mathrm{pH}$} & MO & $\mathrm{P}$ & K & $\mathrm{Al}$ & $\mathrm{Ca}$ & $\mathrm{Mg}$ & $\mathrm{H}+\mathrm{Al}$ & SB & $\mathrm{t}$ & $\mathrm{T}$ & V & $\mathrm{m}$ & $\mathrm{Zn}$ & $\mathrm{Fe}$ & $\mathrm{Mn}$ & $\mathrm{Cu}$ \\
\hline & $\left(\mathrm{dag} \mathrm{kg}^{-1}\right)$ & \multicolumn{2}{|c|}{$\left(\mathrm{mg} \mathrm{dm}^{-3}\right)$} & \multicolumn{7}{|c|}{$\left(\mathrm{cmol}_{\mathrm{c}} \mathrm{dm}^{-3}\right)$} & \multicolumn{2}{|c|}{$(\%)$} & \multicolumn{4}{|c|}{$\left(\mathrm{mg} \mathrm{dm} \mathrm{dm}^{-3}\right)$} \\
\hline 4,9 & 2,95 & 3,4 & 50 & 0,9 & 0,7 & 0,2 & 4,6 & 1,03 & 1,93 & 5,63 & 18,3 & 46,6 & 0,5 & 81,9 & 8,1 & 1,72 \\
\hline
\end{tabular}

1/ Análises realizadas no Laboratório de Análises Físicas e Químicas de Solo do Departamento de Solos da Universidade Federal de Viçosa. pH em água, $\mathrm{KCl}$ e $\mathrm{CaCl}_{2}$ - relação 1:2,5. $\mathrm{P}, \mathrm{Na}, \mathrm{K}, \mathrm{Fe}, \mathrm{Zn}, \mathrm{Mn}, \mathrm{Cu}$ : extrator Mehlich-1. $\mathrm{Al}, \mathrm{Ca}$ e $\mathrm{Mg}$ : extrator $\mathrm{KCl} 1 \mathrm{~mol} \mathrm{~L}^{-1}$. $\mathrm{H}+\mathrm{Al}$ : extrator $\mathrm{Ca}(\mathrm{OAc})_{2} 0,5 \mathrm{~mol} \mathrm{~L}^{-1}$, pH 7,0. 
experimentos distintos. Cada experimento foi composto por seis densidades de plantas daninhas $(0,1,2,3,4$ e 5 plantas por vaso), num delineamento inteiramente casualizado, com quatro repetições.

Mudas de Commelina diffusa foram transplantadas e as demais espécies foram semeadas diretamente nos vasos, aos 30 dias após o transplantio das mudas de café. Para as espécies semeadas, as densidades almejadas foram mantidas por meio de desbastes. O período de interferência ou de convivência (Tabela 2), no mesmo vaso, entre a muda de café e a planta daninha foi considerado como aquele compreendido entre o transplantio (para as espécies transplantadas) ou emergência (para as espécies semeadas) das plantas daninhas e o encerramento dos experimentos, realizado na floração e/ou frutificação das plantas daninhas.

No fim dos experimentos, ao término do período de convivência, para determinação da biomassa seca, procedeu-se à retirada da parte aérea das plantas de café e, também, das plantas daninhas, cortando estas rente ao solo e colocando-as em estufa de circulação forçada de ar, a $70{ }^{\circ} \mathrm{C}$, até massa constante. Todo o material seco foi moído, em moinho tipo Wiley, homogeneizado e amostrado para se fazer a determinação dos teores de macro e micronutrientes na parte aérea, tanto do cafeeiro como das plantas daninhas. A partir da matéria seca da parte aérea e de seus respectivos teores de nutrientes, foram calculados os conteúdos nestas plantas.

Para análise dos teores de macro e micronutrientes, as amostras foram submetidas à digestão nitroperclórica (Allan, 1969), para determinação de $\mathrm{P}, \mathrm{K}, \mathrm{Ca}, \mathrm{Mg}, \mathrm{S}, \mathrm{Zn}, \mathrm{Cu}, \mathrm{Mn}$ e $\mathrm{Fe}$, e à digestão via seca, em mufla a $500{ }^{\circ} \mathrm{C}$, para determinação do $\mathrm{B}$. O N-total foi determinado pelo método Kjeldahl, descrito por Bremner (1965). Tanto o P como o B foram determinados colorimetricamente, sendo o $\mathrm{B}$ pelo método da Azomectina H (Wolf, 1974) e o $\mathrm{P}$ por redução do fosfomolibdato pela vitamina C (Braga \& Defelipo, 1974). O K foi dosado por fotometria de emissão em chama; o S, por turbidimetria do sulfato (Blanchar et al., 1965); e $\mathrm{Ca}, \mathrm{Mg}, \mathrm{Fe}, \mathrm{Zn}$, Cu e $\mathrm{Mn}$, por espectrofotometria de absorção atômica.

Para a interpretação dos resultados foi calculado o conteúdo relativo dos nutrientes na parte aérea de ambas as plantas. Atribuiu-se o valor de $100 \%$ ao conteúdo de nutrientes verificado nas plantas de café que cresceram livres de interferência, na densidade de zero plantas daninhas por vaso. A partir desse valor referencial foram calculados, para as demais densidades, os conteúdos percentuais (conteúdos relativos) de nutrientes na matéria seca das plantas de café e daninhas que conviveram no mesmo vaso. Procedeu-se, portanto, apenas à análise descritiva.

\section{RESULTADOS E DISCUSSÃO}

Os resultados são apresentados com base no conteúdo de nutrientes na parte aérea das plantas, uma vez que, segundo Pitelli (1985), quando se estuda a capacidade das plantas daninhas em competir por nutrientes, deve-se considerar, com maior importância, o acúmulo de matéria seca pela comunidade infestante do

Tabela 2 - Período de convivência (PC), no mesmo vaso, das plantas daninhas com a muda de café

\begin{tabular}{|l|l|c|c|}
\hline \multicolumn{2}{|c|}{ Espécie } & \multirow{2}{*}{${\text { Código }{ }^{-}}^{\prime}$} & PC \\
Nome científico & Nomes comuns ${ }^{\prime}-$ & BIDPI & 77 \\
\hline Bidens pilosa & picão-preto, fura-capa & 180 \\
\hline Commelina diffusa & trapoeraba, maria-mole & COMDI & 82 \\
\hline Leonurus sibiricus & rubim, macaé & LECSI & 68 \\
\hline Nicandra physaloides & joá-de-capote, quintilho & NICPH & 148 \\
\hline Richardia brasiliensis & poaia-branca, poaia & RCHBR & 133 \\
\hline Sida rhombifolia & guanxuma, mata-pasto & SIDRH & 13 \\
\hline
\end{tabular}

1/ Fonte: LORENZI (2000). 
que apenas os teores de nutrientes que essas plantas apresentam. Numa comunidade infestante, uma determinada planta daninha pode apresentar os maiores teores de nutrientes; no entanto, devido à sua baixa produção de biomassa seca, pode apresentar os menores conteúdos destes. Nas Tabelas 3 e 4 são apresentadas as quantidades totais de nutrientes (conteúdos) presentes na parte aérea das plantas de café e daninhas, respectivamente, na forma de conteúdo relativo (CR). Valores inferiores ou superiores a $100 \%$ indicam menor ou maior extração de nutrientes do solo, respectivamente, pelas plantas de café ou pelas plantas daninhas, ou, em se tratando apenas destas últimas, o menor ou maior potencial competitivo dessas espécies com o cafeeiro e, também, entre espécies daninhas.

Tabela 3 - Conteúdo relativo ${ }^{1 /}$ de macro e micronutrientes na parte aérea de plantas de café, cultivadas em vasos, sob a interferência de diferentes densidades de plantas daninhas

\begin{tabular}{|c|c|c|c|c|c|c|c|c|c|c|c|c|c|}
\hline \multirow{2}{*}{ Espécie } & \multirow{2}{*}{$\begin{array}{l}\text { Plantas } \\
\text { por vaso }\end{array}$} & $\mathrm{N}$ & $\mathrm{P}$ & $\mathrm{K}$ & $\mathrm{Ca}$ & $\mathrm{Mg}$ & $\mathrm{S}$ & $\mathrm{Cu}$ & $\mathrm{Zn}$ & B & Mn & $\mathrm{Fe}$ & $\mathrm{Na}$ \\
\hline & & \multicolumn{12}{|c|}{$(\%)$} \\
\hline \multirow{6}{*}{$\begin{array}{l}\text { Bidens } \\
\text { pilosa }\end{array}$} & 0 & 100 & 100 & 100 & 100 & 100 & 100 & 100 & 100 & 100 & 100 & 100 & 100 \\
\hline & 1 & 59 & 72 & 67 & 67 & 74 & 97 & 106 & 66 & 76 & 59 & 54 & 69 \\
\hline & 2 & 47 & 73 & 59 & 62 & 71 & 88 & 75 & 55 & 73 & 53 & 37 & 60 \\
\hline & 3 & 34 & 54 & 42 & 41 & 48 & 59 & 35 & 43 & 48 & 33 & 26 & 42 \\
\hline & 4 & 28 & 45 & 31 & 36 & 39 & 54 & 38 & 36 & 34 & 32 & 25 & 30 \\
\hline & 5 & 28 & 39 & 28 & 31 & 17 & 50 & 45 & 38 & 39 & 28 & 22 & 27 \\
\hline \multirow{6}{*}{$\begin{array}{c}\text { Commelina } \\
\text { diffusa }\end{array}$} & 0 & 100 & 100 & 100 & 100 & 100 & 100 & 100 & 100 & 100 & 100 & 100 & 100 \\
\hline & 1 & 30 & 42 & 37 & 45 & 48 & 69 & 69 & 37 & 54 & 19 & 41 & 35 \\
\hline & 2 & 33 & 51 & 40 & 53 & 56 & 113 & 108 & 40 & 63 & 21 & 55 & 40 \\
\hline & 3 & 18 & 33 & 20 & 30 & 35 & 69 & 78 & 25 & 34 & 11 & 47 & 21 \\
\hline & 4 & 18 & 37 & 25 & 31 & 34 & 62 & 92 & 29 & 42 & 11 & 54 & 24 \\
\hline & 5 & 14 & 29 & 21 & 22 & 25 & 49 & 98 & 18 & 29 & 8 & 62 & 20 \\
\hline \multirow{6}{*}{$\begin{array}{l}\text { Leonurus } \\
\text { sibiricus }\end{array}$} & 0 & 100 & 100 & 100 & 100 & 100 & 100 & 100 & 100 & 100 & 100 & 100 & 100 \\
\hline & 1 & 35 & 33 & 38 & 36 & 40 & 41 & 66 & 37 & 41 & 30 & 57 & 39 \\
\hline & 2 & 31 & 36 & 39 & 31 & 43 & 43 & 47 & 37 & 52 & 24 & 65 & 37 \\
\hline & 3 & 36 & 38 & 42 & 38 & 41 & 51 & 45 & 43 & 53 & 26 & 59 & 44 \\
\hline & 4 & 39 & 44 & 39 & 40 & 44 & 57 & 51 & 55 & 61 & 36 & 72 & 40 \\
\hline & 5 & 37 & 48 & 40 & 43 & 46 & 61 & 52 & 58 & 60 & 31 & 78 & 44 \\
\hline \multirow{6}{*}{$\begin{array}{c}\text { Nicandra } \\
\text { physaloides }\end{array}$} & 0 & 100 & 100 & 100 & 100 & 100 & 100 & 100 & 100 & 100 & 100 & 100 & 100 \\
\hline & 1 & 37 & 62 & 68 & 72 & 76 & 86 & 114 & 69 & 101 & 50 & 107 & 68 \\
\hline & 2 & 37 & 64 & 58 & 73 & 67 & 101 & 88 & 65 & 85 & 58 & 115 & 60 \\
\hline & 3 & 34 & 59 & 50 & 54 & 56 & 83 & 53 & 48 & 71 & 45 & 66 & 52 \\
\hline & 4 & 49 & 83 & 69 & 82 & 81 & 103 & 106 & 76 & 99 & 68 & 115 & 74 \\
\hline & 5 & 44 & 64 & 67 & 72 & 75 & 96 & 89 & 72 & 98 & 45 & 80 & 71 \\
\hline \multirow{6}{*}{$\begin{array}{c}\text { Sida } \\
\text { rhombifolia }\end{array}$} & 0 & 100 & 100 & 100 & 100 & 100 & 100 & 100 & 100 & 100 & 100 & 100 & 100 \\
\hline & 1 & 97 & 83 & 105 & 90 & 88 & 98 & 93 & 77 & 138 & 102 & 80 & 106 \\
\hline & 2 & 73 & 72 & 77 & 71 & 93 & 90 & 56 & 61 & 96 & 78 & 68 & 78 \\
\hline & 3 & 37 & 42 & 49 & 44 & 53 & 56 & 33 & 35 & 90 & 43 & 52 & 49 \\
\hline & 4 & 72 & 62 & 85 & 60 & 81 & 79 & 66 & 63 & 135 & 54 & 91 & 85 \\
\hline & 5 & 36 & 44 & 61 & 39 & 51 & 56 & 36 & 35 & 82 & 37 & 69 & 61 \\
\hline \multirow{6}{*}{$\begin{array}{l}\text { Richardia } \\
\text { brasiliensis }\end{array}$} & 0 & 100 & 100 & 100 & 100 & 100 & 100 & 100 & 100 & 100 & 100 & 100 & 100 \\
\hline & 1 & 49 & 61 & 57 & 53 & 50 & 67 & 43 & 51 & 63 & 57 & 61 & 59 \\
\hline & 2 & 32 & 42 & 48 & 37 & 40 & 48 & 40 & 43 & 45 & 41 & 49 & 47 \\
\hline & 3 & 35 & 33 & 38 & 28 & 36 & 39 & 28 & 34 & 29 & 42 & 34 & 36 \\
\hline & 4 & 43 & 54 & 58 & 51 & 51 & 69 & 52 & 49 & 60 & 47 & 46 & 55 \\
\hline & 5 & 25 & 27 & 40 & 28 & 32 & 41 & 35 & 31 & 32 & 25 & 44 & 38 \\
\hline
\end{tabular}


Tabela 4 - Conteúdo relativo ${ }^{1 /}$ de macro e micronutrientes na parte aérea de plantas daninhas, cultivadas em vasos, em várias densidades, juntamente com uma planta de café

\begin{tabular}{|c|c|c|c|c|c|c|c|c|c|c|c|c|c|}
\hline \multirow{2}{*}{ Espécie } & \multirow{2}{*}{$\begin{array}{l}\text { Plantas } \\
\text { por vaso }\end{array}$} & $\mathrm{N}$ & $\mathrm{P}$ & $\mathrm{K}$ & $\mathrm{Ca}$ & $\mathrm{Mg}$ & $\mathrm{S}$ & $\mathrm{Cu}$ & $\mathrm{Zn}$ & B & $\mathrm{Mn}$ & $\mathrm{Fe}$ & $\mathrm{Na}$ \\
\hline & & \multicolumn{12}{|c|}{$(\%)$} \\
\hline \multirow{6}{*}{$\begin{array}{l}\text { Bidens } \\
\text { pilosa }\end{array}$} & 0 & 100 & 100 & 100 & 100 & 100 & 100 & 100 & 100 & 100 & 100 & 100 & 100 \\
\hline & 1 & 553 & 1.119 & 532 & 451 & 481 & 848 & 1300 & 684 & 524 & 452 & 1.924 & 544 \\
\hline & 2 & 367 & 1.294 & 673 & 509 & 655 & 1.517 & 1326 & 754 & 572 & 520 & 1.466 & 697 \\
\hline & 3 & 422 & 1.349 & 651 & 672 & 803 & 2.086 & 1492 & 964 & 591 & 629 & 1.616 & 687 \\
\hline & 4 & 407 & 1.542 & 607 & 653 & 814 & 1.995 & 1872 & 1.076 & 677 & 674 & 1.357 & 649 \\
\hline & 5 & 400 & 1.418 & 589 & 677 & 936 & 1.945 & 1423 & 848 & 614 & 653 & 1.128 & 641 \\
\hline \multirow{6}{*}{$\begin{array}{l}\text { Leonurus } \\
\text { sibiricus }\end{array}$} & 0 & 100 & 100 & 100 & 100 & 100 & 100 & 100 & 100 & 100 & 100 & 100 & 100 \\
\hline & 1 & 231 & 427 & 525 & 357 & 256 & 603 & 594 & 717 & 755 & 227 & 629 & 547 \\
\hline & 2 & 236 & 479 & 550 & 506 & 294 & 980 & 744 & 850 & 911 & 272 & 879 & 585 \\
\hline & 3 & 202 & 412 & 451 & 450 & 259 & 978 & 656 & 845 & 772 & 255 & 761 & 450 \\
\hline & 4 & 217 & 435 & 288 & 456 & 247 & 1.009 & 641 & 777 & 892 & 269 & 686 & 375 \\
\hline & 5 & 230 & 496 & 383 & 558 & 270 & 1.479 & 604 & 846 & 1.218 & 309 & 844 & 412 \\
\hline \multirow{6}{*}{$\begin{array}{c}\text { Nicandra } \\
\text { physaloides }\end{array}$} & 0 & 100 & 100 & 100 & 100 & 100 & 100 & 100 & 100 & 100 & 100 & 100 & 100 \\
\hline & 1 & 228 & 1.128 & 513 & 411 & 259 & 1.973 & 841 & 694 & 487 & 211 & 492 & 622 \\
\hline & 2 & 275 & 1.348 & 487 & 572 & 302 & 2.749 & 1079 & 869 & 701 & 278 & 685 & 620 \\
\hline & 3 & 275 & 1.634 & 610 & 754 & 372 & 3.287 & 1108 & 929 & 798 & 331 & 649 & 725 \\
\hline & 4 & 253 & 1.613 & 540 & 695 & 359 & 3.442 & 1307 & 879 & 726 & 333 & 605 & 589 \\
\hline & 5 & 301 & 1.734 & 672 & 633 & 357 & 3.174 & 1222 & 980 & 773 & 313 & 743 & 742 \\
\hline \multirow{6}{*}{$\begin{array}{c}\text { Sida } \\
\text { rhombifolia }\end{array}$} & 0 & 100 & 100 & 100 & 100 & 100 & 100 & 100 & 100 & 100 & 100 & 100 & 100 \\
\hline & 1 & 146 & 374 & 220 & 270 & 131 & 195 & 331 & 267 & 295 & 366 & 146 & 249 \\
\hline & 2 & 198 & 627 & 447 & 463 & 255 & 332 & 484 & 476 & 507 & 596 & 284 & 479 \\
\hline & 3 & 149 & 538 & 407 & 473 & 190 & 263 & 569 & 380 & 483 & 357 & 312 & 450 \\
\hline & 4 & 210 & 598 & 442 & 484 & 219 & 334 & 683 & 475 & 530 & 517 & 408 & 483 \\
\hline & 5 & 168 & 618 & 456 & 558 & 206 & 341 & 846 & 500 & 584 & 439 & 435 & 503 \\
\hline \multirow{6}{*}{$\begin{array}{c}\text { Richardia } \\
\text { brasiliensis }\end{array}$} & 0 & 100 & 100 & 100 & 100 & 100 & 100 & 100 & 100 & 100 & 100 & 100 & 100 \\
\hline & 1 & 179 & 205 & 213 & 496 & 136 & 382 & 690 & 1.621 & 197 & 410 & 1.298 & 228 \\
\hline & 2 & 161 & 194 & 258 & 457 & 142 & 390 & 528 & 1.326 & 210 & 403 & 1.262 & 278 \\
\hline & 3 & 239 & 202 & 321 & 503 & 167 & 444 & 631 & 1.495 & 203 & 481 & 1.384 & 331 \\
\hline & 4 & 109 & 175 & 247 & 473 & 144 & 393 & 586 & 887 & 185 & 478 & 1.352 & 253 \\
\hline & 5 & 180 & 178 & 263 & 461 & 136 & 464 & 566 & 698 & 195 & 348 & 1.648 & 273 \\
\hline
\end{tabular}

$\mathrm{O} C \mathrm{CR}$ de macro e micronutrientes na parte aérea de plantas de café foi severamente reduzido devido à interferência de $B$. pilosa. Ademais, ele diminuiu com o aumento da densidade dessa espécie daninha. $\mathrm{O} \mathrm{CR}$, em café, de N (59\%), P (72\%), K (67\%), Ca (67\%), $\mathrm{Mg}(74 \%)$ e S (97\%), na densidade de uma planta por vaso, reduziu para N (28\%), P (39\%), $\mathrm{K}(28 \%)$, Ca (31\%), Mg (17\%) e S (50\%) na densidade de cinco plantas por vaso (Tabela 3). Comportamento análogo foi verificado para os micronutrientes (Tabela 3). Diferentemente do que ocorreu no cafeeiro, o CR em B. pilosa foi extremamente elevado. $\mathrm{Na}$ densidade de apenas uma planta por vaso, o CR foi de $553 \%$
(N), 1.119\% (P), 532\% (K), 451\% (Ca), 481\% (Mg) e $848 \%$ (S) (Tabela 4). Portanto, o acúmulo desses macronutrientes em $B$. pilosa foi 5,53 (N), 11,19 (P), 5,32 (K), 4,51 (Ca), 4,81 (Mg) e 8,48 (S) vezes maior que aquele verificado em plantas de café cultivadas sem a interferência de $B$. pilosa (Tabela 4). Contudo, quando se compara a quantidade de nutrientes extraída por uma planta de $B$. pilosa com aquela extraída por uma planta de café, após a convivência dessas plantas, no mesmo vaso, por 77 dias, verifica-se que $B$. pilosa acumulou 9,37 (N), 15,54 (P), 7,94 (K), 6,73 (Ca), 6,50 (Mg) e $8,74(\mathrm{~S})$ vezes mais nutrientes do que o cafeeiro. 
Considerando apenas a densidade de uma planta por vaso, o CR dos micronutrientes em B. pilosa foi sempre superior a $450 \%$, atingindo os valores máximos de 1.300 e $1.924 \%$ para $\mathrm{Cu}$ e $\mathrm{Fe}$, respectivamente (Tabela 4). O CR desses dois micronutrientes, na planta daninha, foi 12,26 e 35,63 vezes superior ao do cafeeiro. Constatou-se, também, que a quantidade de nutrientes acumulada em $B$. pilosa não variou muito com sua densidade. Logo, devido à sua alta capacidade de extração de nutrientes, mesmo presente na lavoura em baixas densidades, $B$. pilosa poderia reduzir a disponibilidade de nutrientes para o cafeeiro. Mal nutrido, o cafeeiro teria seu crescimento e potencial de competição com a planta daninha cada vez menores, tornando-se, inclusive, mais sensivel ao ataque de patógenos.

Commelina diffusa foi uma das espécies que proporcionou as maiores reduções no $\mathrm{CR}$ em plantas de café, com exceção de S, Cu e Fe. Isso ocorreu devido ao maior grau de competição, causado, principalmente, pelo longo período de convivência entre a cultura e a planta daninha (180 dias) (Tabela 2). Apesar de presentes, as diferenças no CR, em cafeeiro, foram pequenas entre as densidades estudadas. Verificou-se, portanto, na densidade de cinco plantas por vaso, $\mathrm{CR}$ inferior a $20 \%$ para $\mathrm{N}, \mathrm{Zn}$ e Mn e entre 20 e $30 \%$ para $\mathrm{P}, \mathrm{K}, \mathrm{Ca}, \mathrm{Mg}$ e B (Tabela 3). De modo geral, o reduzido conteúdo de nutrientes foi reflexo da baixa produção de massa seca pelas plantas de café (dados não apresentados), devido à redução no crescimento das plantas, imposta pela interferência de C. diffusa. Oliveira et al. (2002) verificaram reduções no diâmetro do caule, no número de folhas e na altura de plantas de café quando infestadas por diferentes espécies de Commelina.

O CR em plantas de café também foi severamente reduzido pela interferência de L. sibiricus, tanto em baixas (com 1-2 plantas por vaso) quanto em altas densidades (com 4-5 plantas por vaso), não existindo diferenças consideráveis entre elas. Da mesma forma, o $\mathrm{CR}$ de cada nutriente, com exceção do $\mathrm{S}$, na parte aérea dessa planta daninha foi o mesmo, nas diferentes densidades estudadas. Isso ocorreu porque não houve efeito da densidade de $L$. sibiricus na sua produção de biomassa (dados não mostrados). Em relação à planta daninha, à medida que sua densidade nos vasos aumentou, o acúmulo de biomassa e, conseqüentemente, o de nutrientes, de cada planta, diminuíram, de forma que o acúmulo final foi o mesmo, para as baixas ou altas densidades. Segundo Radosevich et al. (1996), o crescimento individual das plantas daninhas decresce com o aumento de sua densidade, ou seja, em baixas densidades, a produção total de biomassa é determinada por poucas plantas grandes, enquanto em altas densidades é determinada por muitas plantas pequenas. Esse tipo de relação entre densidade e produtividade de plantas é conhecido como a "lei do rendimento final constante". Ademais, como com o aumento da densidade determinado nivel (número) de indivíduos é alcançado, a partir do qual a interferência ocorre entre plantas vizinhas, verificouse, neste experimento, além da competição interespecífica entre café e $L$. sibiricus, a ocorrência de competição intra-específica entre indivíduos dessa espécie daninha.

Considerando apenas a densidade de uma planta de $L$. sibiricus por vaso, uma vez que não houve diferenças entre densidades, verificou-se pequeno $\mathrm{CR}$, em café, de $\mathrm{N}(35 \%)$, $\mathrm{P}(33 \%), \mathrm{K}(38 \%)$, Ca (36\%), Mg (40\%) e S (41\%) (Tabela 3), enquanto em $L$. sibiricus os macronutrientes acumularam-se em muito maior extensão: N (232\%), P (427\%), K (525\%), Ca (357\%), Mg (256\%) e S (603\%) (Tabela 4). Logo, convivendo no mesmo vaso por 82 dias, uma planta de $L$. sibiricus acumulou 6,60 (N), 12,94 $(\mathrm{P}), 13,82(\mathrm{~K}), 9,92(\mathrm{Ca}), 6,40(\mathrm{Mg})$ e 14,71 (S) vezes mais nutrientes do que o cafeeiro. Analogamente, para os micronutrientes $(\mathrm{Cu}, \mathrm{Zn}, \mathrm{B}$, $\mathrm{Mn}, \mathrm{Fe}$ e $\mathrm{Na}$ ), seus acúmulos nessa planta daninha foram, em média, 13,24 vezes maiores que no cafeeiro (Tabela 4).

Nicandra physaloides foi a espécie daninha que menos afetou o CR em plantas de café, com exceção de N e Mn. O CR no cafeeiro permaneceu estável com o aumento da densidade; contudo, em $N$. physaloides, aumentou com o aumento da sua densidade. Esse aumento ocorreu devido à maior produção de biomassa dessa planta daninha em densidades mais altas (dados não apresentados). Após planta daninha e cultura conviverem juntas, no mesmo vaso, por 68 dias, na densidade de uma planta por vaso, verificou-se que o $\mathrm{CR}$, em café, foi de $\mathrm{N}(37 \%), \mathrm{P}(62 \%), \mathrm{K}(68 \%)$, Ca (72\%), Mg (76\%) 
e S $(86 \%)$ (Tabela 3) e, em N. physaloides, de N (228\%), P (1.128\%), K (513\%), Ca (411\%), Mg (259\%) e S (1.973\%) (Tabela 4), portanto, diferentes entre si em 6,16 (N), 18,19 (P), $7,54(\mathrm{~K}), 5,71(\mathrm{Ca}), 3,41(\mathrm{Mg})$ e 22,94 (S) vezes. Essas relações aumentaram para 6,84 (N), 27,09 (P), 10,03 (K), 8,79 (Ca), 4,76 (Mg) e 33,06 (S) quando se considerou a densidade de cinco plantas de N. physaloides por vaso.

Com o aumento da densidade de S. rhombifolia nos vasos, houve decréscimo do CR em plantas de café e aumento no CR na planta daninha. O CR de N (97\%), P (83\%), K $(105 \%)$, Ca (90\%), Mg (88\%) e S $(98 \%) \%$, nas plantas de café infestadas por apenas um individuo de $S$. rhombifolia, reduziu para $\mathrm{N}$ (36\%), P (44\%), K (61\%), Ca (39\%), Mg (51\%) e $\mathrm{S}(56 \%)$, quando infestadas por cinco plantas dessa espécie daninha (Tabela 3). Na planta daninha, o CR de N (146\%), P (374\%), K (220\%), Ca $(270 \%), \operatorname{Mg}(131 \%)$ e S (195\%), na densidade de uma planta por vaso, aumentou para $\mathrm{N}$ (168\%), P (618\%), K (456\%), Ca (558\%), Mg $(206 \%)$ e S $(341 \%)$ na densidade de cinco plantas por vaso (Tabela 4). Logo, na densidade de uma planta por vaso, S. rhombifolia acumulou, em média, 2,43 vezes mais macronutrientes do que o cafeeiro. Para os micronutrientes, essa relação foi de 2,82 vezes. Na densidade de cinco plantas por vaso, as relações de macro e micronutrientes aumentaram para 7,81 e 11,89, respectivamente.

A interferência de $R$. brasiliensis sobre o café, após convivência por 148 dias, consistiu na redução do CR de todos os nutrientes na parte aérea do cafeeiro, que aumentou com o incremento da densidade de $R$. brasiliensis. O CR de N (49\%), P (61\%), K (57\%), Ca (53\%), Mg $(50 \%)$ e S $(67 \%) \%$, nas plantas de café infestadas por apenas um individuo de $R$. brasiliensis, reduziu para N (25\%), P (27\%), K (40\%), Ca (28\%), Mg (32\%) e S (41\%) quando a infestação aumentou para cinco plantas por vaso (Tabela 3). Na planta daninha, o CR teve o mesmo comportamento da sua produção de biomassa seca (dados não apresentados), ou seja, não aumentou com o incremento da densidade, mas foi sempre superior a $100 \%$. Na densidade de uma planta de $R$. brasiliensis por vaso, o CR foi de N (179\%), P (205\%), K (213\%), Ca (496\%), Mg (136\%), S (382\%), Cu (690\%), Zn (1691\%), B (197\%), Mn (410\%), Fe
(1298\%) e Na (228\%) (Tabela 4). Quando se calcula a relação desses valores com aqueles encontrados no cafeeiro, verifica-se, em média, 4,76 e 13,88 vezes mais macro e micronutrientes, respectivamente, na planta daninha, com destaque para $\mathrm{Zn}$ e $\mathrm{Fe}$, cujas relações foram de 31,78 e 21,28, respectivamente.

Singh \& Singh (1939), estudando o crescimento de plantas daninhas e o acúmulo de nutrientes durante seu ciclo de vida, verificaram que: a produção de matéria seca e a absorção de nutrientes foram altamente influenciadas pelo estádio de desenvolvimento da planta; no estádio de pré-florescimento as plantas daninhas apresentam as máximas taxas de acúmulo de biomassa e de absorção de nutrientes; no pré-florescimento, também, as plantas daninhas apresentam os mais altos teores de nutrientes, os quais são muito maiores do que aqueles verificados na maioria das culturas agrícolas; e tanto a taxa como a ordem de absorção de nutrientes variam entre plantas daninhas. Confirmando os estudos de Singh $\&$ Singh (1939), os resultados do presente experimento sinalizam para que o manejo de plantas daninhas em lavouras em formação e/ou adultas deva ser realizado antes que as plantas daninhas atinjam o florescimento, principalmente quando ainda são jovens, pois, além do menor gasto de energia e da maior facilidade no seu controle, a competição por nutrientes com o cafeeiro será ainda pequena.

B. pilosa, C. diffusa, L. sibiricus e $R$. brasiliensis, mesmo em baixas densidades, acarretaram decréscimos consideráveis no conteúdo relativo de nutrientes de plantas de café. $B$. pilosa foi a planta daninha que extraiu a maior quantidade de nutrientes, enquanto $N$. physaloides e S. rhombifolia foram as espécies que causaram menor interferência no cafeeiro. O grau de interferência (ou de competição) variou com a espécie e com a densidade das plantas daninhas.

\section{LITERATURA CITADA}

ALLAN, J. E. Varian Aerograph/Varian Techtron. Bulletin 12/69:A:-1010. 15 p. 1969.

BARBOUR, M. G.; BURK, J. H.; PITTS, W. D. Terrestrial plant ecology. 2.ed. Menlo Park: Benjamin Cummings, 1987. 
BLANCHAR, R. W.; REHM, G.; CALDWELL, A. C. Sulfur in plant material by digestion with nitric and perchloric acid. Proc. Soil Sci. Soc. Am., v. 29, p. 71-72, 1965.

BLANCO, H. G. A importância dos estudos ecológicos nos programas de controle das plantas daninhas. Biológico, v. 38, n. 10, p. $343-350,1972$.

BLANCO, H. G.; OLIVEIRA, D. A. Estudos dos efeitos da época de controle do mato sobre a produção de citros e a composição da flora daninha. Biológico, v. 45, n. 1, p. 2536,1978 .

BLANCO, H. G.; OLIVEIRA, D. A.; PUPO, E. I. H. Período de competição de uma comunidade natural de mato em uma cultura de café em formação. Biológico, v. 48, n. 1, p. 9-20, 1982.

BRAGA, J. M.; DEFELIPO, B. Determinação espectrofotométrica de fósforo em extrato de solos e plantas. R. Ceres, v. 21, p. 73-85, 1974.

BREMNER, J. M. Total nitrogen. In: BLACK, C. A. (Ed.) Methods of soil analysis. Madison: American Society of Agronomy, 1965. part 2. p. 1149-1179.

BRIGHENTI, A. M. Plantas daninhas. In: COSTA, E. B.; SILVA, A. E. S.; NETO, A. P. M. A.; DAHER, F. A., (Coords.) Manual técnico para a cultura do café no Estado do Espírito Santo. Vitória: SEAG-ES, 1995. p. 90-106.

COUSENS, R. Aspects of the design and interpretation of competition (interference) experiments. Weed Technol., v. 5, p. 664-673, 1991.

FRIESSLEBEN, U.; POHLAN, J.; FRANKI, G. The response of Coffea arabica L. to weed competition. Café, Cacao Thé, v. 35, n. 1, p. 15-20, 1991.

GALLO, J. R. et al. Absorção de nutrientes pelas ervas daninhas e sua competição com o cafeeiro. B. Inst. Agron., n. 104, p. $1-13,1958$.

HARPER, J. L. The population biology of plants. London: Academic Press, 1977. 892 p.
LORENZI, H. Manual de identificação e controle de plantas daninhas: plantio direto e convencional. 5.ed. Nova Odessa, Plantarum, 2000. 384 p.

McNAUGHTON, S. J.; WOLF, L. L. General ecology. Ney York: Holt, Rinchart and Winston, 1973. 710 p.

OLIVEIRA, A. R.; FREITAS, S. P.; VIEIRA, H. D. Efeito da competiçào de trapoerabas no crescimento de plantas de café (Coffea arabica) recém-transplantadas. In: CONGRESSO BRASILEIRO DA CIÊNCIA DAS PLANTAS DANINHAS, 23., 2002, Gramado, RS. Resumos... Londrina: SBCPD/EMBRAPA Clima Temperado, 2002. p. 461.

PEREIRA, H. C.; JONES, P. A. A tillage study in kenya coffee. Part I: The effects of tillage practices on coffee yields. Emp. J. Exp. Agric., v. 22, n. 87, p. 231-240, 1954.

PITELLI, R. A. Interferência de plantas daninhas em culturas agrícolas. Inf. Agropec., v. 120, n. 11, p. 16-27, 1985.

RADOSEVICH, S. R. Methods to study interactions among crops and weeds. Weed Technol., v. 1, p. 190-198, 1987.

RADOSEVICH, S. R.; HOLT, J.; GHERSA, C. Physiological aspects of competition. In: Weed ecology: Implication for managements. New York: John Willey \& Sons, 1996. p. 217-301.

SINGH, B. N.; SINGH, L. B. Relative absorption of nutrients by weeds of arable land. Soil Sci., v. 47, p. 227235, 1939.

TOLEDO, S. V.; MORAES, M. V.; BARROS, I. Efeito da freqüência de capinas na produção do cafeeiro. Bragantia, v. 55, n. 2, p. 317-324, 1996.

WOLF, B. Improvements in azomethine-H method for determination of boron. Comm. Soil Sci. Plant. Anal. v. 5, p. 39-44, 1974.

ZAKHARENKO, V. A. Investigating the competitive ability of weeds and crop plants in relation to herbicide application. Weed Abstr., v. 18, n. 3, art. 1271, 1969. 